\title{
An Analytic Hierarchy Process (AHP) Framework for Feature Evaluation of Smart Electricity Meters in India
}

\author{
Krishna Priya, G.S. \\ Centre for Urban Science and \\ Engineering \\ Indian Institute of Technology Bombay \\ Mumbai, India \\ https://orcid.org/0000-0001-7727-0867 \\ Santanu Bandyopadhyay \\ Department of Energy Science and \\ Engineering \\ Indian Institute of Technology Bombay \\ Mumbai, India \\ santanub@iitb.ac.in
}

\author{
Gobind Pillai \\ School of Computing, Engineering and \\ Digital Technologies \\ Teesside University \\ Middlesbrough, UK \\ g.g.pillai@tees.ac.uk \\ Tracey Crosbie \\ School of Computing, Engineering and \\ Digital Technologies \\ Teesside University \\ Middlesbrough, UK \\ t.crosbie@tees.ac.uk
}

\author{
Arnab Jana \\ Centre for Urban Science and \\ Engineering \\ Indian Institute of Technology Bombay \\ Mumbai, India \\ arnab.jana@iitb.ac.in \\ Dana Abi Ghanem \\ School of Computing, Engineering and \\ Digital Technologies \\ Teesside University \\ Middlesbrough, UK \\ d.abighanem@tees.ac.uk
}

\begin{abstract}
This paper presents a methodology for assessing the smartness required of an electricity meter for affordable, inclusive, and sustainable electricity access in the Global South. The multicriteria decision making tool Analytic Hierarchy Process (AHP) is utilised for developing a framework for assessing smartness. The framework relies on input from experts to assign specific weights to various criteria contributing to smartness. As an example, a select few meters available in India are evaluated based on their smartness score and affordable costs, and the insights obtained are discussed. It is shown that the framework developed provides a new means for selecting smart meters cost-effectively without compromising on sustainability.
\end{abstract}

Keywords-smart metering, Analytic Hierarchy Process Process, Global South, sustainability, Sustainable Development Goal

\section{INTRODUCTION}

The United Nation's (UN) Sustainable Development Goals (SDGs) offer a guide to a more sustainable future for all, that places environmental degradation, sustainability, climate change, and energy water security under the international spotlight. There are 17 SDGs in total. SDG 11 aims to make cities inclusive, safe, resilient, and sustainable which is key to a more sustainable future for all of mankind. Rapid urbanisation is resulting in a growing number of slum dwellers, inadequate and overburdened infrastructure and services, worsening air pollution and unplanned urban sprawl. Many of the UN's SDGs are interconnected. For example, without affordable and clean energy for all (SDG 7) it is impossible to imagine an inclusive safe resilient city. It is therefore clear that improving our energy infrastructure is central to meeting SDG 11 . In this context electricity meters are key gateway technologies that control access to electricity services, which are basic requirements for health, economic growth, and wellbeing [1].

Metering of consumption is essential to the efficient operation and planning of electricity networks. However, it is often lacking or not fit for purpose in the Global South, leading national and international agencies, and governments to encourage the introduction of 'smarter' more comprehensive metering in the electricity and water sectors. This paper proposes a framework for investigating the degree of smartness an electricity meter is required to have to best serve the needs of those in the Global South sustainably. This framework is applied using the Mumbai region and the electricity sector of India at large as an example. The rollout of smart metering (or advanced metering infrastructure) has begun in India but is yet to happen on a large scale, which makes this research very timely. The overarching research question addressed in this paper is How 'smart' does a smart electricity meter need to be to contribute to meeting cities affordable, inclusive, and sustainable as needed to meet the UN sustainable Development Goal 11 (SDG11)?

In order to carry out this investigation, the work presented explores various types of electricity meters available in the country, and identifies key criteria based on which these can be compared. A group of experts then evaluate these criteria and grade them on their relative importance, thereby allowing for multicriteria decision making regarding the smartness required of an electricity meter using Analytic Hierarchy Process (AHP) for meeting UN SDGs. There have been studies on implications of smart metering in India [2] and its impact on sustainability [3]. However, there is still a lack of understanding regarding the degree of smartness required to achieve sustainable development. Given that smart metering is a significant investment for distribution companies in India such a study is of practical significance.

\section{Methodology}

Smart electricity metering is relatively new trend in India, necessitated by an amendment to the Electricity Act of 2003 [4]. The amendment, enacted in 2019, specifically stated that all consumer meters installed should be smart meters. Additionally, only smart meters are to be installed at new connections, while existing consumer meters are to be replaced by smart meters over a specified timeframe. The overall aim is to improve transparency, billing efficiency, and reducing Aggregate Technical \& Commercial (AT\&C) losses in general. It is hoped that higher energy efficiency and reduction of non-technical losses; including theft, meter 
tampering, and non-payment; facilitated by smart meters can aid in improving the overall financial health of distribution companies which are largely at a loss in India [5].

Various methods are available in literature for multicriteria decision making such as those based on Fuzzy Theories, Case Based Reasoning (CBR), Goal Programming, etc. [6]. Each of these methods have specific advantages. For example, goal programming can generate an infinite number of alternative solutions [7]. Meanwhile, CBR can process inconsistencies specific to certain events that may not produce a viable solution in other methods [8]

In the choice of one meter over another, the decision makers will have to compare various factors that cannot directly be quantified. Analytical Hierarchical Processing (AHP) is ideally suited as it can take the opinions of experts and stakeholders and convert them into numeric weights, thereby allowing for easy decision making. AHP has been applied in the choice of one technology or instrument over another by multiple researchers [9] [10]. Therefore, AHP is a valid decision-making tool for the selection of meter features and has been selected in this work. Proposed by Saaty [11], AHP provides a rational decision-making framework when the criteria and alternatives involved are not directly quantifiable. AHP works on allowing stakeholders to evaluate multiple decision criteria and their relative importance by means of pairwise comparisons between criteria/sub criteria. These evaluations then form a weightage matrix that aids in decision making.

\section{A. Metering Technology in India}

The project team have conducted reviews of smart electricity meter designs, with differing information and communication technology complexities (the data set can be accessed from https://research.tees.ac.uk/en/persons/gobindgopalakrishna-pillai), as well as the utilities' metering requirements and practices. Based on this the AHP structure as shown in Fig. 1 which has four main features that are relevant to meter selection in India and various sub features has been formed. The features and their relevance are described below in short.

\section{1) Functionality}

A key reason for employing smart meters in India is to aid the distribution companies in effectively recovering the billed amount (electricity usage cost). This factor judges the functionality of the meter from the perspective of the distribution company (Discom). The pilot projects on smart metering tested so far in India concentrate heavily on prepaid facility, as well as having the ability to remotely disconnect services in the event of non-payment after a notice period. In addition, low maintenance is also an important feature from the perspective of Discoms. Similarly, most cities in India have multiple distribution companies operating in the same space. Interoperability of meters is also key in such situations as a purchase of additional metering equipment for changing service provided in both expensive and inefficient. Hence, the pairwise comparison between these three subcategories are to be carried out in the AHP.

\section{2) Security}

Security of the meter as well as the data collected is of critical importance and is assessed by this factor. Security is divided further into two subcategories, security against tampering at meter location (such as with illegal connections or theft) and the security of the data collected including customer information. These two subcategories are to be ranked relatively in the AHP.

\section{3) Sustainability}

Smart metering is an integral part of sustainable electricity use as metering facilitates the efficient use of energy. Four sub-criteria that are relevant in this regard are as discussed:

a) Customer Engagement: By providing customers with access to data and alerts related to usage patterns, smart meters can help customers minimise their energy usage.

b) Load Management: By facilitating measures such as time of day tariff, utilities can use smart meters to modify customer behaviour, reducing peak load, and improving system reliability. This can also aid in integrating renewable energy systems to the grid.

c) Data generation: By providing detailed usage data, smart meters can help Discoms identify usage patterns, potential seasonal and daily variations, daily load profiles, etc. This can in turn help identify areas where interventions for better energy utilisation is possible.

d) Meter Life: A higher meter life can lead to less electronic waste, reduced replacement costs and better overall utilisation of the meter.

\section{4) Communication}

This particular criterion deals with how electricity consumption (usage) data can be obtained by the service provider. Since all meters have a physical access port, the key difference here is in wireless communication technology. The three technologies specified by the Central Electricity Authority of India are power line communication (PLC) which uses existing power lines for data transfer, radio Frequency (RF) communication, and cellular communication. It should be noted that since no meter is likely to employ more than one of these, a pairwise comparison is irrelevant. Instead, for analysis they are ranked in order of preference.

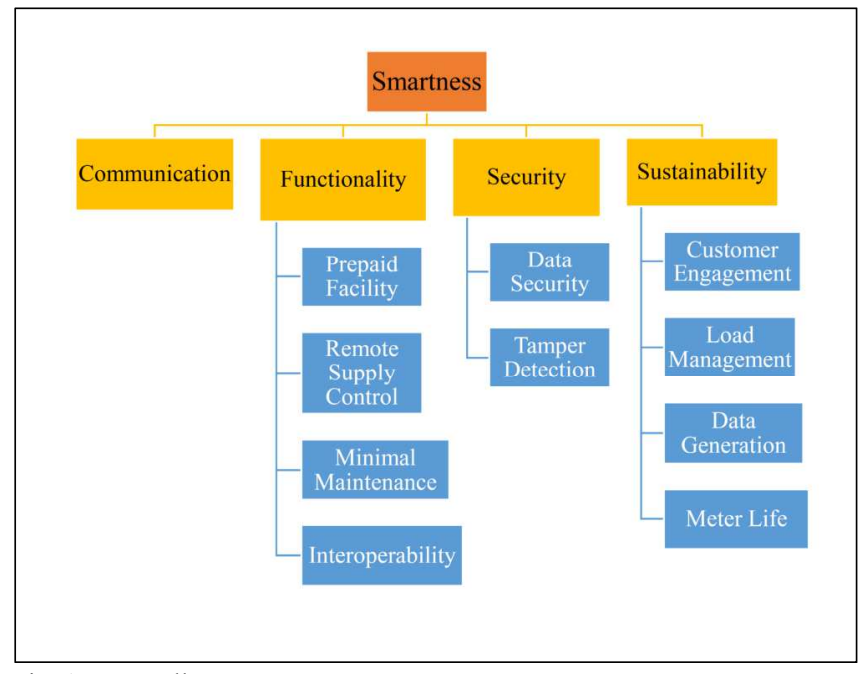

Fig. 1. Overall AHP structure

The next stage in the AHP process is a survey of experts to obtain data for the calculation of priority weights of each 
feature/sub-feature in the AHP. This research study was carried out as part of the British Academy "What is in a Meter? Working Towards Efficient, Socially Inclusive and Environmentally Sensitive Energy and Water Infrastructures in the Global South" project which has project members in the Electrical Power, Energy, Built Environment, Urban Development, Social Sciences and Health disciplines from the UK and India. The participants for the survey were the project team. Given the diversity of tasks, focus areas and expertise within the project team, the idea is that the AHP will help the project team to aggregate their collective view in a structured manner and give a framework for "how smart a smart electricity meter should be" for achieving SDG 11 . The "inclusivity", and "sustainability" elements of SDG11 are inherently addressed in the AHP framework. Meanwhile, the "affordability" element of SDG11 is kept external to the framework as costs and economics are straightforward to quantify.

\section{ANALYSIS}

The data for AHP analysis was collected by means of an anonymised online survey. Six data samples were obtained at the end of the survey. Using conventional AHP analysis, the weights for each criterion and sub-criteria were obtained. In the communication criteria, since meters usually do not employ multiple communication technologies simultaneously, the order of preference chosen was essentially employed as weights. The most preferred, which was mobile communication was given a weight of $1, \mathrm{RF}$ technology 0.67 , and PLC 0.33 based on feedback from target group.

The basic mathematical model of AHP is explained briefly below. AHP works on the principle of pairwise comparison between any two decision criteria. For any given set of criteria, a set of weights can be obtained from pairwise comparison.

$$
\left[\begin{array}{cccccc} 
& C_{1} & \ldots & C_{j} & & C_{n} \\
C_{1} & a_{1,1} & \ldots & a_{1, j} & \ldots & a_{1, n} \\
\ldots & \ldots & & \ldots & & \ldots \\
C_{i} & a_{i, 1} & \ldots & a_{i, j} & \ldots & a_{i, n} \\
\ldots & \ldots & & \ldots & & \ldots \\
C_{n} & a_{n, 1} & \ldots & a_{n, j} & \ldots & a_{n, n}
\end{array}\right]
$$

Here,

$$
a_{i, j}=1 \forall i=j
$$

Additionally,

$$
a_{i, j}=1 / a_{j, i}
$$

By normalising the matrix and summing the values obtained in each row, the weights associated with each criterion can be obtained.

Normalised element

$$
X_{i, j}={ }^{a_{i, j}} / \sum_{n}^{j=1} a_{i, j}
$$

The weights corresponding to any element $C_{i}$
$W_{i}=\sum_{n}^{j=1} X_{i, j}$

Knowing the weights, the consistency measure for each criterion can be obtained as

$\lambda_{i}=\sum_{n}^{j=1} a_{i, j} * W_{j}$

The consistency index

$C I=\left(\left(\frac{1}{n} \sum_{n}^{i=1} \lambda_{i}\right)-n\right) /(n-1)$

As an example, the analysis of weights related to the four main criteria is illustrated below. The four main criteria and the pairwise weights obtained by averaging the survey results is provided below.

$\left[\begin{array}{ccccc} & \text { Communication } & \text { Functionality } & \text { Security } & \text { Sustainability } \\ \text { Communication } & 1 & 1.67 & 1 & 2.33 \\ \text { Functionality } & 0.59 & 1 & 3.33 & 1.67 \\ \text { Security } & 1 & 0.30 & 1 & 4 \\ \text { Sustainability } & 0.43 & 0.59 & 0.25 & 1\end{array}\right]$

The normalised values are:

$\left[\begin{array}{ccccc} & \text { Communication } & \text { Functionality } & \text { Security } & \text { Sustainability } \\ \text { Communication } & 0.33 & 0.47 & 0.18 & 0.26 \\ \text { Functionality } & 0.19 & 0.28 & 0.60 & 0.19 \\ \text { Security } & 0.33 & 0.08 & 0.18 & 0.44 \\ \text { Sustainability } & 0.14 & 0.17 & 0.04 & 0.11\end{array}\right]$

The weights so obtained are

$\left[\begin{array}{cc}\text { Communication } & 0.31 \\ \text { Functionality } & 0.31 \\ \text { Security } & 0.26 \\ \text { Sustainability } & 0.12\end{array}\right]$

Similarly, the weights were computed for each set of criteria and sub-criteria. The values so obtained are given in Fig.2. The consistency index and consistency ratio associated with each set of criteria is given below in Table 2 .

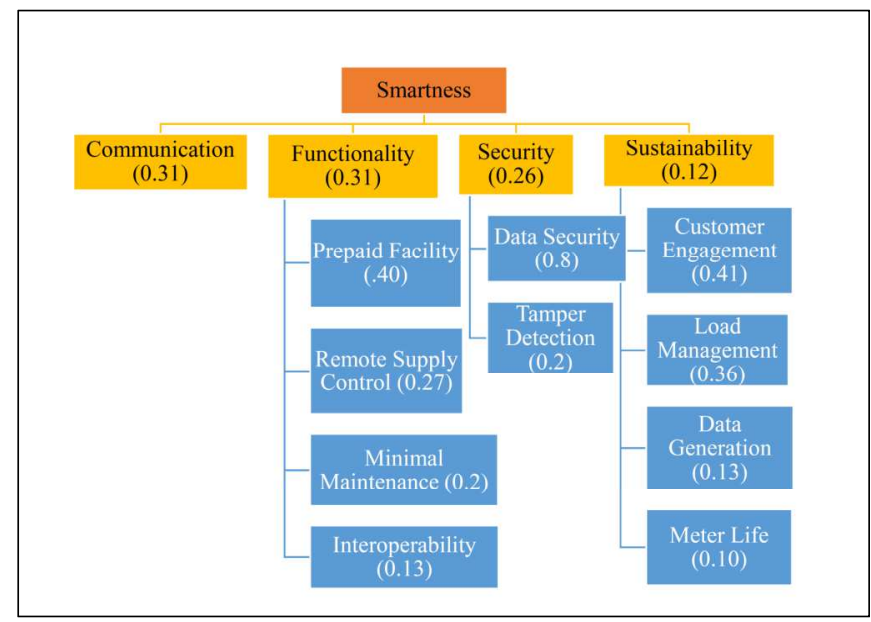

Fig. 2. Selection Criteria and Weights

TABLE I. CONSISTENCY INDEX AND CONSISTENCY RATIO FOR MAIN CRITERIA

\begin{tabular}{|c|c|c|}
\hline & Consistency Index & Consistency Ratio \\
\hline Main Criteria & 0.17 & 0.19 \\
\hline $\begin{array}{c}\text { Sub criteria for } \\
\text { Functionality }\end{array}$ & 0.17 & 0.19 \\
\hline $\begin{array}{c}\text { Sub criteria for } \\
\text { Sustainability }\end{array}$ & 0.12 & 0.13 \\
\hline
\end{tabular}


While ideally the consistency index should have a value less than 0.01, given the small sample set and the diverse points of focus of the sample group (which consisted of engineers and social scientists), the values obtained are acceptable for this illustrative study.

The meters are graded using these weights obtained (Fig. 2 ) and summed to calculate the aggregate weighed smartness score. The values of smartness score for each meter is provided in Table 3 along with their cost in US Dollars (USD) (based on data set mention in Section II.A). It should be noted that the costs presented here are values for purchase of one meter obtained from commercial suppliers. Commercially, a distribution company in India tenders out its meter requirement, the costs are therefore expected to be different. However, these do serve as representative values for the purposes of this study.

TABLE II. SMARTNESS SCORE AND COST OF METERS

\begin{tabular}{|c|c|c|c|}
\hline & $\begin{array}{c}\text { Meter } \\
\text { identifier/name }\end{array}$ & Smartness Score & $\begin{array}{c}\text { Meter Cost } \\
\text { (USD) }\end{array}$ \\
\hline $\begin{array}{l}\text { Single } \\
\text { Phase }\end{array}$ & $\mathrm{A}$ & 0.3463 & 17 \\
\cline { 2 - 4 } & $\mathrm{B}$ & 0.9508 & 64 \\
\cline { 2 - 4 } & $\mathrm{C}$ & 0.6408 & 14 \\
\hline \multirow{3}{*}{$\begin{array}{c}\text { Three } \\
\text { Phase }\end{array}$} & $\mathrm{D}$ & 0.3983 & 114 \\
\cline { 2 - 4 } & $\mathrm{E}$ & 0.9508 & 71 \\
\cline { 2 - 4 } & $\mathrm{F}$ & 0.2251 & 57 \\
\cline { 2 - 4 } & $\mathrm{G}$ & 0.6591 & 100 \\
\hline
\end{tabular}

Purchasing Power Parity (PPP) is a macroeconomic metric that can be used to compare the productivity and living standards between nations. PPP estimates based on per capita Gross Domestic Product (GDP) is available from the IMF (International Monetary Fund) [12]. According to IMF's 2021 estimates UK's PPP is 6.42 time that of India. The average cost of a 3 -phase smart meter in the UK is $£ 300$ (USD 424) for 3-phase and $£ 150$ (USD 212) for single phase. Using the UK as the benchmark, based on PPP an affordable 3phase meter in India should cost around USD 66 and a single phase one USD 33. A plot of cost vs smartness score is given in Fig. 3.

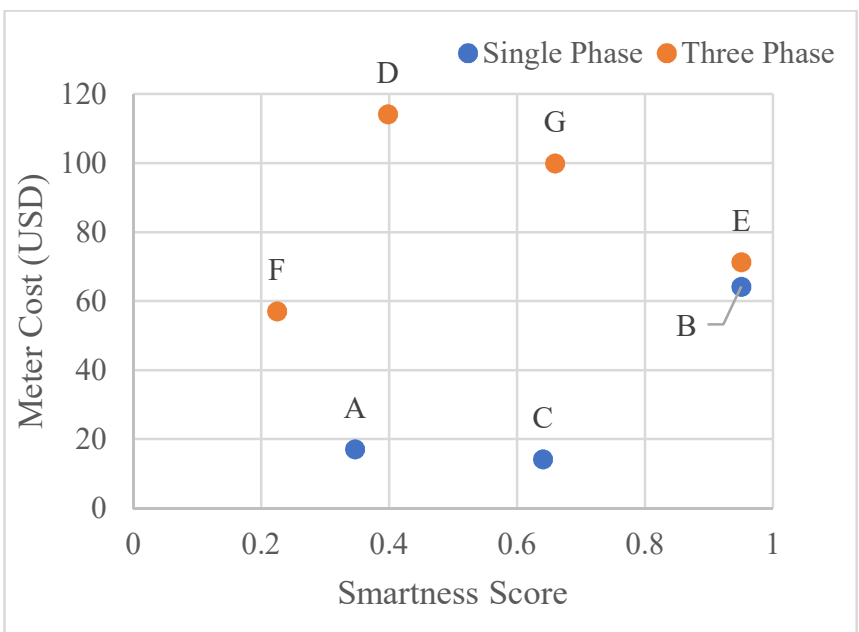

Fig. 3. Meter cost and smartness score
The meters which have a higher cost have additional features that are not accounted for in this analysis. While these features may be relevant in a different context, they do not contribute to smartness as measured here.

It is interesting to note that there is no direct correlation between cost and smartness. For example, the three-phase meter $\mathrm{E}$ has a higher smartness score and a lower cost than D. Similarly, while meters B and E, have comparable costs and identical smartness scores, $\mathrm{B}$ is designed for a single-phase system while $\mathrm{E}$ is for a three-phase system. It is therefore interesting to note that a high degree of smartness is almost equally expensive, whether targeting single phase connections (that cater to low usage customers) or three phase connections (which cater to customers with a higher electrical load). Additionally, meter E, which is the smartest in the three-phase category also has a moderate cost when D and G. In a three-phase connection, meter $E$ provides a high smartness score while simultaneously having a lower cost than its competitors D and G. This is likely due to the fact that meters $\mathrm{D}$ and $\mathrm{G}$ have additional features that do not contribute to smartness, thereby increasing the cost. Similarly, meters A and $\mathrm{C}$ have very similar cost values, though meter $\mathrm{C}$ has a higher smartness score.

The answer to the question 'How 'smart' does a smart electricity meter need to be to contribute to meeting cities affordable, inclusive, and sustainable as needed to meet SDG11?" in terms of smartness score is the higher the better. Bringing affordability into the picture, using a target of around USD 66 for 3-phase and USD 33 for single phase meters, for the data set we have used in this study meters E and $\mathrm{C}$ respectively seem to meet the requirements best. There is a caveat here that, the cost values are likely to be different from the study for distribution companies as they do bulk purchases based on tenders.

\section{CONCLUSIONS}

This work presents a method for evaluating smartness of an electricity meter in the context of sustainable electricity access. The smartness score obtained alongside a cost comparison, can be used to identify cost-effective smart metering options from available alternatives without compromising on sustainable development. The illustrated examples show the highest smartness score may not correspond to the most complex (in terms of number of available features) and expensive meters. Considering affordability, meters at an affordable price point are available at a relatively high smartness score. In fact, of the options considered, the second most affordable three phase meter (E) is also the smartest. Similarly, meter $\mathrm{C}$ is an optimal choice for single phase meters.

It is evident that it is possible to manufacture smart electricity meters that can facilitate affordable, inclusive, and sustainable electricity access as needed to meet the UN SDG11 in the Global South at a low cost. Large scale manufacturing and bulk purchases based on tenders can additionally bring the meter cost values down for distribution companies. By considering the meter smartness score along with cost, decision makers can make informed and effective decisions regarding the choice of a smart electricity meter such that the requirements of SDG 11 are met. 


\section{ACKNOWLEDGMENT}

The research presented in this paper is part of a research project entitled "What is in a meter? Working towards efficient, socially inclusive and environmentally sensitive energy and water infrastructures in the Global South." The project is funded through the British Academy's Urban Infrastructures of Well-Being Programme 2019, supported under the Global Challenges Research Fund (Reference: UWB190097). The authors wish to acknowledge the British Academy for their support.

\section{REFERENCES}

[1] S. Marvin, H. Chappells, \& S. Guy, "Smart meters as obligatory intermediaries: Reconstructing environmental action", Shaping Urban Infrastructures, Routledge, 2012, pp. 189-205.

[2] P. Bansal, \& A. Singh, "Smart metering in smart grid framework: A review", Fourth International Conference on Parallel, Distributed and Grid Computing (PDGC). IEEE.December 2016, pp. 174-176.

[3] K. T. Chui, M. D. Lytras, \& A. Visvizi, "Energy sustainability in smart cities: Artificial intelligence, smart monitoring, and optimization of energy consumption", Energies, 11(11), 2018, 2869.

[4] Ministry of Power, Draft Amendment in the Electricity Act, 2003 to Introduce key Reforms in the Power Sector, 2020. Available at $<$ pib.gov.in/PressReleasePage.aspx?PRID $=1615781>$ Accessed on 30 Jan 2021
[5] The World Bank, Data Catalogue:World Development Indicators, 2020. Available at $<$ datacatalog.worldbank.org/> Accessed on 30 Jan 2021

[6] M. Velasquez, \& P. T. Hester, "An analysis of multi-criteria decision making methods". International journal of operations research, 10(2), 2013, pp. 56-66.

[7] K. Ukherjee, \& A. Bera, "Application of goal programming in project selection decision - A case study from the Indian Coal mining industry", European Journal of Operational Research, 82(1), 1995, pp. 18-25.

[8] H. Li, \& J. Sun, "Ranking-order case-based reasoning for financial distress prediction". Knowledge-Based Systems, 21(8), 2008, pp. 868878.

[9] E. B. Sloane, M. J. Liberatore, R. L. Nydick, W. Luo, \& Q. B. Chung, "Clinical engineering technology assessment decision support: a case study using the analytic hierarchy process (AHP”). Proceedings of the Second Joint 24th Annual Conference and the Annual Fall Meeting of the Biomedical Engineering Society][Engineering in Medicine and Biology (Vol. 3, pp. 1950-1951). IEEE. October 2002.

[10] S. Ozdemir, \& G. Sahin, "Multi-criteria decision-making in the location selection for a solar PV power plant using AHP". Measurement, 129, 2018, pp. 218-226.

[11] T. Saaty, The analytic hierarchy process: Planning, priority setting, resource allocation, McGraw-Hill, New York, 1980.

[12] Internatioal Monetary Fund, "World Economic and Financial Surveys", World Economic Outlook Database, 2021. Available at https://www.imf.org/en/Publications/WEO/weodatabase/2021/April/weo-report. Accessed on 30 Jan 2021 